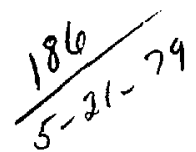

\title{
AUTOMATING THE ANALYTICAL LABORATORIES SECTION, LEWIS RESEARCH CENTER, NATIONAL AERONAUTICS AND SPACE ADMINISTRATION: A FEASIBILITY STUDY
}

\author{
W. G. Boyle \\ G. W. Barton
}

March 15, 1979

Work performed under the zuspices of the U.S. Department of

Energy by the UCLLL under contract number W-7405.ENG.48

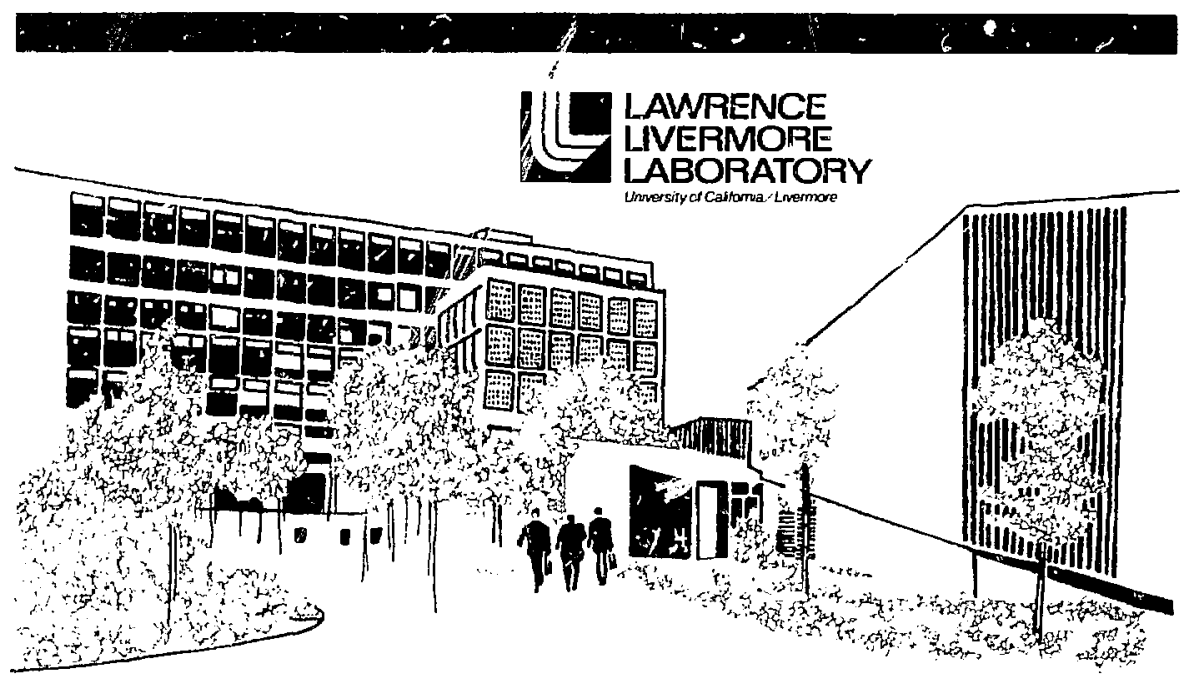




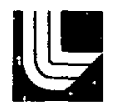

LAWFENCE IIVERMORE LABORATOİAY

Linversity of Caltornia Liverisrore.Calitornia 94550

UCRL-52594

\section{AUTOMATING THE ANALYTICAL LABORATORIES SECTION, LEWIS RESEARCH CENTER, NATIONAL AERONAUTICS AND SPACE ADMINISTRATION: A FEASIBILITY STUDY}

W. G. Boyle

G. W. Barton

MS. date: March 15, 1979

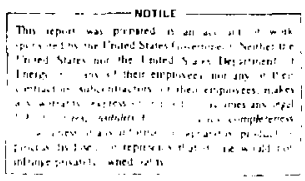




\section{FOREWORD}

Lawrence Livermore Laboratory performed this work for the National Aeronautics and Space Administration under task order number YCG6747. 


\section{CONTENTS}

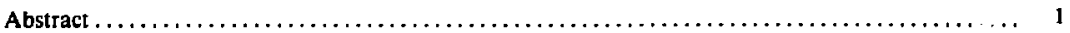

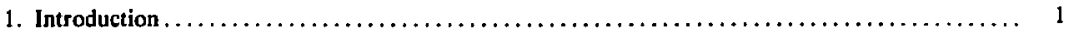

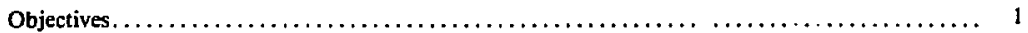

Automation Experience at Lawrence Livermore Laboratory $\ldots \ldots \ldots \ldots \ldots \ldots \ldots \ldots \ldots \ldots, \quad 1$

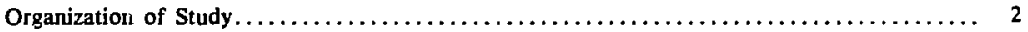

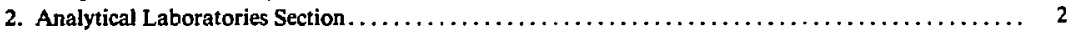

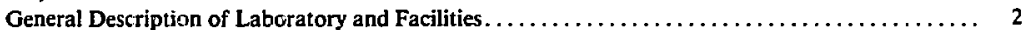

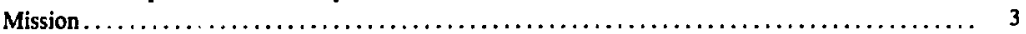

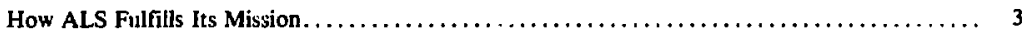

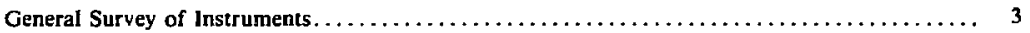

Sample Logging, Data Flow, Reports, and Record Keeping $\ldots \ldots \ldots \ldots \ldots \ldots \ldots \ldots \ldots \ldots$ s

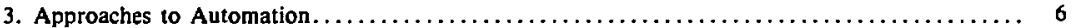

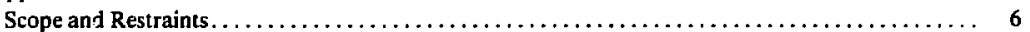

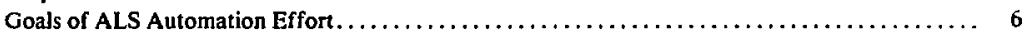

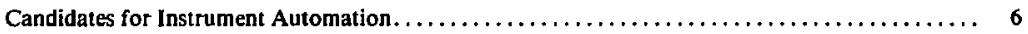

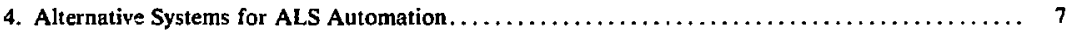

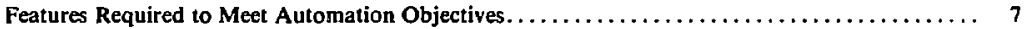

Alternative Systems $\ldots \ldots \ldots \ldots \ldots \ldots \ldots \ldots \ldots \ldots \ldots \ldots \ldots \ldots \ldots \ldots \ldots \ldots \ldots \ldots \ldots, 8$

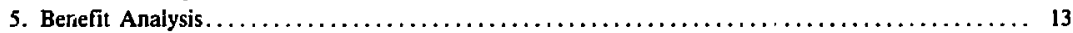

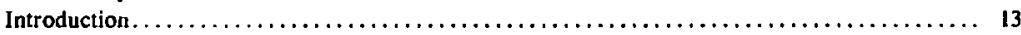

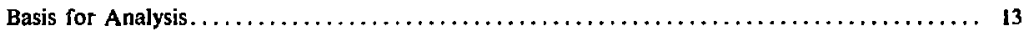

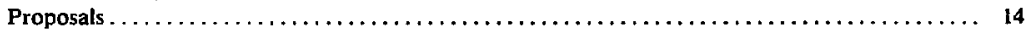

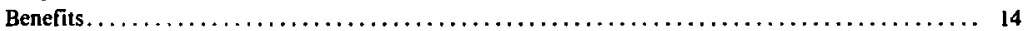

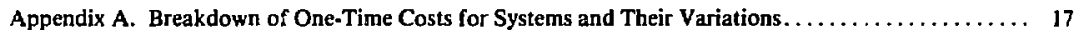

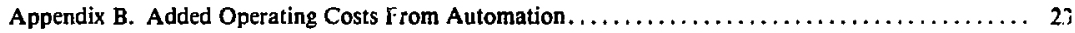

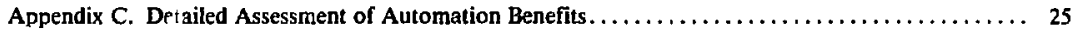




\title{
AUTOMATING THE ANALYTICAL LABORÁTORIES SECTION, LEWIS RESEARCH CENTER, NATIONAL AERONAUTICS AND SPACE ADMINISTRATION: A FEASIBILITY STUDY
}

\begin{abstract}
We studied the feasibility of computerized automation of the Analytical Laboratories Section at NASA's Lewis Research Center. Since that laboratory's duties are not routine, we set our automation goals with that in mind. We selected four instruments is the most likely automation candidates: an atomic absorption spectrophotometer, an emission spectrometer, an x-ray fluorescence spectrometer, and an x-ray diffraction unit.

Our study describes two options for computer automation: a time-shared central computer and a system with microcumputers for each instrument connected to a central computer. A third option, presented for future planning, expands the microcomputer version. We determine costs and benefits for each option. And we conclude that the microcomputer version best fits the goals and duties of the laboratory and that such an automated system is needed to meet the laboratory's future requirements.
\end{abstract}

\section{INTRODUCTION}

\section{OBJECTIVES}

This study seeks to define current and future automation requirements of the Analytical Laboratories Section (ALS), Materials Characterization and Operations Branch, NASA Lewis Research Cenier (LeRC), Cleveland, Ohio. We propose several different alternative plans tor fuifilling those requirements and present analyses of the costs and benefits of these alternatives. The basic data and information for this study was developed through interviews with the ALS staff

ALS has already expended considerable effort attempting to automate some of its instruments. These efforts have resulted in some benefits, but have not been done under an overall integrated approach to laboratory automation that could easily be expanded or changed as the situation required. ALS has also benefited by using the central computer facilities at LeRC. We find, however, many disadvantages to an uncoordinated antomation effort and in too heavy a reliance on remote computer facilities designed for sophisticated data reduction. We propose alternatives to overcone these disadvantages and hence to approach more closely the ideal concept of laboratories that can perform many parameter determinations simultaneously, quickly, and accurately.

\section{AUTOMATION EXPERIENCE AT LAWRENCE LIVERMORE LABORATORY}

Since 1966, with the installation of the PDP-7 computer in its General Chemistry Division (CCD), Lawrence Livermore Laboratory (LLL) has been deeply involved with and in the forefront of computer automation of chemical analyses, both in time-shared and stand-alone modes. Since 1973, the Environmental Research Center of the U.S. Environmental Protection Agency (EPA) in Cincinnati and members of GCD, working together, have specified, designed, and placed in operation three laboratory automation systems. GCD has remained as a consultant to the EPA for continuing advice and service and to help develop new systems at other EPA laboratories. In addition, GCD has specified and installed automation systems for The U.S. Geological Survey (USGS) National Water Quality Laboratories in Denver and Atlanta. 


\section{ORGANIZATION OF STUDY}

Section 2 of this report describes the ALS facilities and gives a general outline of the character of its laboratory. From this description we develop joals and candjdates for instrumentation in Section 3. In Section 4 we discuss several plans for automation. Section 5 discusses the components of these systems and summarizes the costs and benefits from details found in Appendices A, B, and C.

\section{ANALYTICAL LABORATORIES SECTION}

\section{GENERAL DESCRIPTION OF LABORATORY ANB FACILITIES}

ALS is part of the Materials Characterization and Operations Branch, with William Gordon as its section chief. The section consists of 13 people, professional and technical. It has three units: the Emission Spectrochemical Analysis and X-Ray Diffraction Unit, the Chemical Analysis Unit, and the Electron Optics Unit (Fig. I).

The Emission Spectrochemical Analysis and $X$-Ray Diffraction Unit has two emission spectrometers operating simultaneously from a common source, two $x$-ray diffractometers, and four $\mathrm{x}$-ray sources for Debye-Scherrer and Guinier-de Wolff cameras. The Chemical Analysis Unit possesses one atomic-absorption instrument, an $x$-ray fluorescence unit, and three LECO instruments for inert-gas fusion, carton determinations, and nitrogen-oxygen $(\mathrm{N}-\mathrm{O})$ determinations. It also has a vacuum fusion analyzer and the usual instruments associated with wet chemical analysis such as analytical balances, $\mathrm{pH}$ meters, and two spectrophotometers. The Electron Optics Unil has a scanning electron microscope (available for use by outside operators), a scanning transmission electron microscope, and an electron microprobe.

The Central Computer Facility at LeRC consists of an IBM 360/67 computer operating in the time-share mode. Input to it comes mainly from a MODCOMP-III computer operating a 3-megabyte tixed-head disk called a "data collector". About a dozen PDP-11's located in a room adjacent to the 360 send data to the data collector. These PDP-11's are controllers and data concentrators for remote microcomputer-based data takers. Data may aiso be sent by terminal. This scheme works best for large data-generating experiments such as wind tunnel tests, but has not worked as well for chemistry instrumentation. Experiments depend on equipment availability and must be scheduled at least two days in advance. Uncerain response times are often not suitable for instruments that generate many small sets of data each day.
FIG. 1. The Aualytleal Laboratodes Section (ALS) at Lewis Reserrch Center, Cleveland, Ohlo.

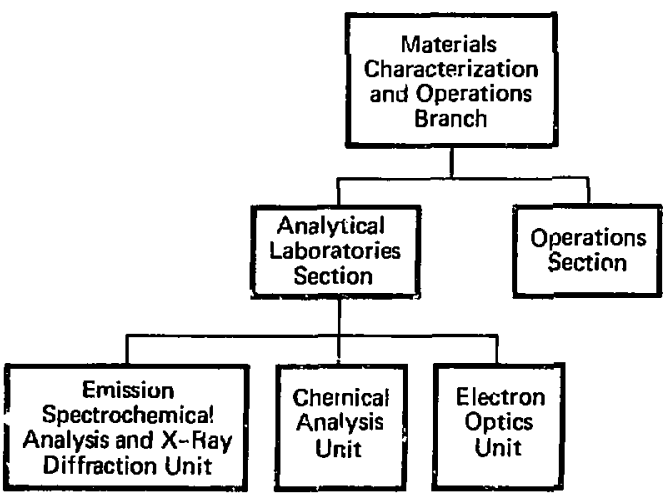




\section{MISSION}

The general ALS mission is to aid various LeRC facilities and contractors in their projects. The program in Cleveland now includes such pro. jects as highway vehicle propulsion under primarily a Department of Energy transfer of funcis, new types of wind turbines, and apprication of photovoltaic devices. Thus, much of the work consists of special problems and often requires a good deal of method development. In this respect, ALS's work is very similar to GCD's work at LLL. The samples are often unusual alloys, cermets, and specimens for troubleshooting problems with mechanical assemblies.

Analytical requests are for a wide range of measurements on a wide variety of materials. Some typical examplcs are identification of deposits left on a substrate, quantitative analysis of the components of an alioy, analysis of diesel exhaust, and detirmination of impurities in shale-oil fuel and how these impurities might affect corrosion problems. The laboratory participates in "round-robin" evaluations of analytical procedures, and it may be called to be the final judge in the arbitration of differences in analytical measurements. It also consults and advises on technical problems and recommends commercial analytical laboratories.

There are, however, a certain number of routine analyses. These analyses associated with specific projects may continue for the duration of the project. Hence, the overall work of the laboratory is an ever-changing mix of method development, sample running, and special problems.

\section{HOW ALS FULFILLS ITS MISSION}

It follows that ALS must use a variety of techniques in solving problems presented to it. That is, it must frequently develop new meihods or modify existing methods. This varying sample type requires that ALS maintain personnel, expertise, and equipment able to respond quickly and competently.

As a result, ALS personnel have employed a number of teciniques using computers to assist in gathering and interpreting data. Some of these computers are built into the instrument to control instrument settings, such as found in the $x$-ray fluorescence instrument; others are on direct: line to the entral computer facility, such as with the emission spectrometer. For solving special problems in emission spectrometry and $x$-ray diffraction, ALS uses photographic plate readers. Sometimes data reduction is accomplished by entering data by hand either into a programmable calculator or into the central computer facility.

These computerization techniques have been successful enough to justify a more integrated approach to the automation of ALS iacilities.

\section{GENERAL SURVEY OF INSTRUMENTS}

\section{Chemical Analysis Unit}

Besides doing conventional wet chemical analyses this unit works with three LECO instruments for determining carbon, oxygen, and nitrogen; an atomic-absorption instrument for trace metal analysis; and a vacuum fusion apparatus.

Atomic-Absorption Spectropinotometer (AAS), Instrumentation Lab Model-153. This AAS is around 10 years old. It is a double-channel instrument with two beams in each channel. Since we have automated an AAS like thi- hefore, it would be relatively inexpensive to transfer the automation to this one. This instrument is likely to be replaced soon and if so, a basic unit will be purchased. An AAS automated into a general system will give much more flexibility in operation than the currently available AAS's with built-in microprocessors. Such spectrophotometers are strictly limited to the software the manufacturer provides, and this software is generally directed toward multiple running of routine samples.

This concept is further supported if an inductively coupled plasma spectrometer (ICP) is purchased. The AAS will then be relegated to running samples, which the ICP is not as capable of doing, and flexibility of operation will be even more important.

We recommend that an AAS be autonaled and that it be one without an original-equipment microprocessor.

Inert-Gas Analyzer, LECo 734-100. This instrument is 15 years old, but is still used frequently for oxygen determinations in the range of 0.5 to $5 \%$ and for samples that do not release their oxygen fast enough for the LECO TC-30 instrument (see below). It uses an induction furnace to heat the 
sample and convert the oxygen to carbon dioxide $\left(\mathrm{CO}_{2}\right)$. The $\mathrm{CO}_{2}$ is eventually released from a molecular sieve trap, and the readout is from a thermal-conductivity cell. A Varias 475 digital integrator integrates the peak. The system is calibrated by injecting $\mathrm{CO}_{2}$ through a gas-sampling valve and constructing a calibration curve.

Since this instrument uses a constructed calibration curve, it would be helped by online data taking, which could consiruct a calibration curve and return answers immediately However, the instrument is 15 years old and is used only in special situations, so automation would have low priority.

N-O Determinator, LECO TC-30. This apparatus consists of a high-current furnace to combust the sample, a cupric oxide $(\mathrm{CuO})$ furnace to convert carbon monoxide $(\mathrm{CO})$ to $\mathrm{CO}_{2}$ and e. silica gel column to separate the $\mathrm{CO}_{2}$ from the nitrogen $\left(\mathrm{N}_{2}\right)$. A thermal cunductivity readout produce: the signal which is read on two digital voltmeters; one for $\mathrm{CO}_{2}$ and one for $\mathrm{N}_{2}$. A one-point calibration curve is used, and weight differences between standarit and sample are compensated by means of a dial on the instrumt'nt. This instrument would benefit from automation designed to transfer the analytical resulis to a data management system for quality assurance calculations. Otherwise, automa.ion woukl probably not improve the normal operation of the instrument.

Carbon Determinator, LECO ELC-12. This is the slandard induction-furnace carbon determination in which the sample is burned in a stream of oxygen. The output comes from a thermal. conductivity cell. A LECO EB-26 electronic balance is wired into the apparatus, ard this automatically infrits the weight of the sample. Readout is automatically in concentration. There is also a calibration control for weight corrections. This instrumer: also has a low priority for automation. A data management system might justify placing this instrument online.

Vacuum Fusion-Gas Analyzer, National Jesearch NRC-912. This commercial vacuum fusion analyzer uses fusion in a platinum bath to release $\mathrm{CO}$, hydrogen $\left(\mathrm{H}_{2}\right)$ and $\mathrm{N}_{2}$ from samples. The combined total is measured by pressurevolume-temperature techniques (using a McLeod gage). The gases are then pumped over $\mathrm{CuO}$ and dried with magnesium perchlorate; then $\mathrm{CO}_{2}$ plus $\mathrm{N}_{2}$ is measured. Finally, the $\mathrm{CO}_{2}$ is frozen out and $\mathrm{N}_{2}$ alone is measured. This instrument is used mostly for referee samples and to settle disputes. LLL's vacu::m fusion analyzer now automated on our PDP-7 is generally similar in operation. A study of the problem of redesigning the software and hardware of LLL's vacuum fusion apparatus to move the system from GCD's PDP-7 to the modern ECLIPSE computer concluded that it would no: be cost beneficial. In the LLL study the two most persuasive elements leading to this conclusion were that (1) the demand for vacuu, fusion analyses was low and (2) when needed could be provided rompetently by commercial laboratories. Since the use factor for the ALS instrument is also low, the LLL conclusions probably apply to the NRC-912 vacuum fusion instrument. Thus it should not be automated.

X-Ray Fluorescence Spectrometer, Diano XRD-s000. This is a standard $x$-ray fluorescence setup with the Diano XRD-8000 controller and readout. It is us :d for buth qualitative and quantitative analysis. Samples are often put into solution for analysis on the instrument. The XRD-8000 has a microprocessor that can control and display the settings of a number of parameters involving the $x$-ray generator, counting tube, pulse-heisit selection, amplifier gain, and scaler timer. The final readings are in counts and are printed on a teletype. Matrix corrections are not used as yet. A calibration curve is produced using an electronic calculator. Programs that handle the calibration and display the curves would be desirable. Also, the goniometer could be controlled by the computer for scanning. The control of the goniometer and calculational algorithms, using a long form and a short form $\mathrm{e}^{\mathrm{f}} \mathrm{a}$ modified Birk's matrix con ection program, are currently being developed at LLL for another project. LLL's expertise can be transferred to this instrt. ment, which is a good candidate for automation.

\section{Emission Spectroscopy and X-Yay Diffraction Unit}

Alomic-Emission Spectroscopy. The laboratory has two emission spectroscopes: a 3.4-m Jarrell-Ash spectrograph ind a 1.5-m Jarrell-Ash spectrometer. These instruments are optically coupled for simultaneous use with either a spark source or a controlled-atmosphere arc source. Data from the spectrometer are automatically sent to the computer center and filed on the disks of the $360 / 67$. Data from the spectrograph will soon be read by a Joyce-Loebl reader, locally controlled by a PDP-11/05. 
A fairly large effort has been expended to automate the $1.5-\mathrm{m}$ spectrometer. At the present time this automation suffers from several faults ranging from noise problems to slow turnaround time. LLL has automated an emission spectrometer and could apply this knowledge here.

LLL has also alitomated a Jarrell-Ash microphotometer using a precision screw driven by a stepping motor. However, the sirew drive would sometimes pcrmit a line to be totally missed on automated plate scans. Ail interactive program, which allowed the operator to manually position the microphotometer head at the beginning of each line of interest and the computer to then take over the scan, was quite satisfactory for the quantitative analysis of selected elements.

The reading of the spectrographic plates would benefit from LLL experience with computerassisted plate readers.

X-Ray Diffraction. This facility has two diffractometers as weil as a r,umber of Debye-Scherrer and Guinier-de Wolff cameras. These are used primarily for phase identification in metal and ceramic samples. An automated plate reader is available, but a satisfactory data reduction algorithm for the central computer facility has not been written. Automated readout, even if slow, would relieve the load on the staff. A faster way than the handsorting of recipe cards to access the standard crystallographic library would also be very desirable.

Much of the work in automating $x$-ray diffractometry is now being done at LLL in another division. Whether a significant part of this work could be transferred to the NASA facilities depends on (1) the similarity between the work and (2) the degree of generality built into the LLL programs. The automated plate-reader data reduction algorithms would probably have to be developed as a separate project. If this technology were transferred to ALS ii would simplify automating at least part of the $x$-ray diffractometry instrumentation.

\section{Electron Microscopy Unit}

The Electron Microscopy Unit has two automated electron microscupes: one scanning, with a NOVA-1 10 controller, and one transmission, with a PDP-11/05. In addition to the usual studies, it would be desirable to find a way to reduce elestron diffraction patterns produced in the transmission microscope. The unit also has an ARL electron microprobe. It outputs its data to a silent -700 teleprinter, $t$ at for final reduction the data is hand typed into the IBM 360.

The automation problems here are somewhat similar to the x-ray diffraction problems. In addition, the transmission microscope produces photographic plates, and it would be very desirable to have at least a computer-assisted readout for these. The electron microprobe needs to he put online. The scanning, id transmission electron microscopes need the' 'puts tied to a dato management system.

\section{SAMPLE LOGGING, DATA FLOW, REPORTS, AND RECORD-KEEPING}

About $95 \%$ of the samples received at ALS are walk-in samples. The remaining $5 \%$ are associated with continuing projects of some kind.

The person requesting analysis fills out a request form, submits the samples, and enters the appropriate data in a logbook. Each section keeps a separate logbook. Sample numbers are assigned consecutively as samples are received. Identifying numbers furnished by the requesters are also recorded. Local samples are shared with the other units. Reporis are informal and varied depending on the information requested by the submitter. Often the rer.uester discusses the problem directly with the analytical section involved.

The general atmosphere of the laboratory is informal and rexible, which is appropriate for handling a variety of analytical problems that of ten require discussion and method-development. Any automation system must take this situation into account and allow a maximum of interaction with the users. The automation system must also be versatile and allow for frequent user program changes while the user system is running and performing aralytical determinations. The large und varied number of requestors also suggests a data management system carefully designed to provide the proper inputs with a minimum of operator interaction. 


\section{APPROACHES TO AUTOMATION}

\section{SCOPE ANL RESTRAINTS}

In our introduction we mentioned that ALS is a cection of the Materials Characterization and Operations Branch. We recognize that other tranches of the Materials and Structure Division would benefit from an in-house computer system. This study considers only a computer system that s ould address the needs of chemistry and clcsely related operations and allow ALS to handlo a greate: laboratory workload with quick response and high rsliability.

Although $\bar{L} L L$ has been actively engaged in analytical shemistry computer automation for over ten years, and in transferring that expertise since 1973, some of the instrusuents covered in this study have not been included in any of the former projects. Thus, it is prudent that automation proceed in an orderly fashion.

\section{GOALS OF ALS AUTOMATION EFFOR'T}

The goals of ALS can be reduced to two fundamental objectives: (I) respond quickly to analysis requests and (2) perform analyses with optimum accuracy and reliability. These are continuing goals, and to meet them in the past has required acquisition of new analytical instruments and staff involvement in dcveltoping manual calculational and graphical methods. Further improvements are possible through the use of computer automation in the laboratory. The objectives are to provide the means to

- improve method development using a flexible system;

- link individual laboratory instruments into a system that will acquire anó process data and perform quality control tests;

- store the data for subsequent recall for compilatron of a summary analysis report;

- determine quality control results during the time samples are being run;

- assure the integrity of the analytical data and its retention (backup) so no data can be altered or lost;
- lessen the number of transcriptions of data and perform calculations more rapidly;

- reduce or eliminate possible errors made in the above steps;

- enter data offline from low-use ald nonautomated methoids;

- $\log$ in samples, their identity, descriptions, the analyses requested, changes in analytical requests, and other information pertinent to the analyses to be performed and the eventual report to be compiled;

- determine the status of individual or groups of samples and the parameters completed relative to the study plan; and

- list work schedules of samples or parameters to be run.

\section{CANDIDATES FOR INSTRUMENT AUTOMATION}

Two of the instruments in the list have already been automated by LLL in previous projects. These are the atomic-absorption spectrophotometer and the direct-reading emission spectrometer (quantometer). LLL has software and hardware designs that would allow an economical implementation. At the present time another division of LLZ is engaged in automating $x$-ray diffraction and fluorescence units used in metallographic applirntions. Many of the techniques developed in this automation project could be applied to ALS.

We have selected four instruments from those surveyed as the first candidates for computer automation. The emphasis on these four instruments does not mean that the other instruments have been ignored, but that current requiremenis will be better served by first developing a basic autor ation system with some representative instrumen. This will enable ALS to evaluate the system and plan for optimization and expansion. Since phctographic plates are a result of the x-ray diffraction unit and emission spectrograph as well as of other instruments, a system will be proposed s'rat will be versatile enough to allow the future development of a plate reader and of a method to use data from existing plate readers. 
We propose as an initial phase the automatton of the AA spactrophotometer, the Diano XRI spectrometer, the emissiun spectroscope direct reader, and an $x$-ray diffraction unit.
We also have included in the study a system encompassing all the instruments deem.d suitable for auiemation. This system has been developed io show whire an orderly approach might lead and to suggest ultimate costs.

\section{ALTERNÁATVE SYSTEMS FOR ALS AUTOMÁ IION}

\section{FEATURES REQUIRED TO MEET AUTOMATION OBJECTIVES}

This section describes the features required to achieve the automation objectives listed ir Sec. 3.

- To maxinize instrument capacity, the computer must be able to take readings from the instrument output at the time a sample signal is present and to sense and control the introduction of new samples. Concentrations are calculated immediately, and quality control checks are made onstream. On fully automatic instruments, the operator is notified immediately if something goes wrong with a run so it can be corrected. On semimanual operations, the cornputer saves time between samples by relteving the operator of the need to read and calculate concentrations.

- Digital reading of the instruments by a compuier is more objective than visual reading and often covers a broader dynamic range. In addition, accuracy is improved by using some of the incrcased sample capacity that the compite: provides to run more standards, spikes, and duplicates.

- Computer automatirn provides two important kinds of quality assurance $(Q A)$. The first kind of $Q A$ is passive; it results from the fact that the fluw of information is always under computer supervision, with no hand transcription of data once it is entered into the system. If the sysiem makes a mistake, it is almost invariably :he kind of mistake that humans find prepostercus. Such errors are easy to spot.

- The second kind of QA provided by computer is active. The arithmetic power of the computer permits easy implementation of analysis algorithms and statistical tests, which are laborious to de by pencil and paper or even with a modern hand calculator. The analyat must prepare duplicate samples and standards and spike a certain fraction of samples. This added effort is minimal.
These two kinds of $Q A$ alert the operator to trends in syitem behavior and permit corrective action before, or as soon as, obvicis false results are produced.

- The computer easily handles the tedious, rept:itive work that operators have done in the past and frees them for tasks that better use their talents. There are several major ways the computer helps the analyst. It reads all the data and calculates the concentration of samples and the curves for standards, displaying this information immediately so the analyst can plan his work more effectively. With more extensive data storage, the analyst will be able to list a set of samples for a particular test from the system storage and to arrange the list of samples in a pattern that may include check standards and :erun samples. The analvat will be able to obiain a summary of work that needs is be done and work that has bec. . Ione, and to create tables if output data. If will also be pcssible to setrieve stortd data, interparameter quality contrel values, and accep: ance limits to help with dilutions and alert operators and users to sanipics that need special attention.

- The computer saves clerical time and reduces clerical errers because it eliminates all hand transcription of information and data after the initial sample-identifying information has been entered. It will print reporis suitable for filing or distribution and will maintain an inventory logbook.

- At least one month's accumulation of anelysis data should be able to be stored in computer system files. These data can be associated with everything known about the sarple. With the proper software, information can be made avajlable in a variety of firmats for report preparation. It can also be used to look at trends of instrumental behavior (for example, calibration drift), check quality control parameters, and prepare work accolntability reporis. Information on certain unique 
analyses should be accessible through the computer indefinitely,

- An automation system should have certain other features to be effective. The computer system should easily be able to accommodate added instruments and perform added automatic functions The need for help from personnel outside the automated laboratory should be minimized. The operator should be able to use the computer as a powerful calculator offline. The latoratory scientist must be able to make necessary changes when nerw information, procedures, and operations are instituted.

\section{ALTERNATYYE SYSTEMS}

We chose the alternative systems for ALS bearing in mind the scope, objectives, and restraints discussed earlier.

Allernative $I$ and $I A$. The candidate instrumerits and auxiliery services are tied to a central ALS host conıputer.

Alternative 2. Each candidate instrument is tied to its own microcomputer. These microcumputers are in turn connected to a central microcomputer along with the auxiliary services (point-topoint network).
Alternative $2 \boldsymbol{A}$. The candidate instrütents and auxiliary services are tied to an interconnected network of microcomputers (multinodal network).

Alternative 3. A combination of alternatives 1 and 2, which could handle all current instruments, allow for future expansion, and have complete data management facilities.

Each of the above systems would have a means of transmitting data to the Central Computer Facility of LeRC's Computer Services Division.

\section{System 1}

Figure 2 shows System 1. This system incorporates a minicomputer for time-shared data acquisition, processing, and centrol and for data management functions.

High-use analytical instruments are placed online to the time-share computer. Input/output terminals are available to each instrument, and data storage backup is provided by a magnetic tape unit at the computer.

The system should include appropriate input/ output terminals at the online and oflline instruments and the ability to program in high-level language.

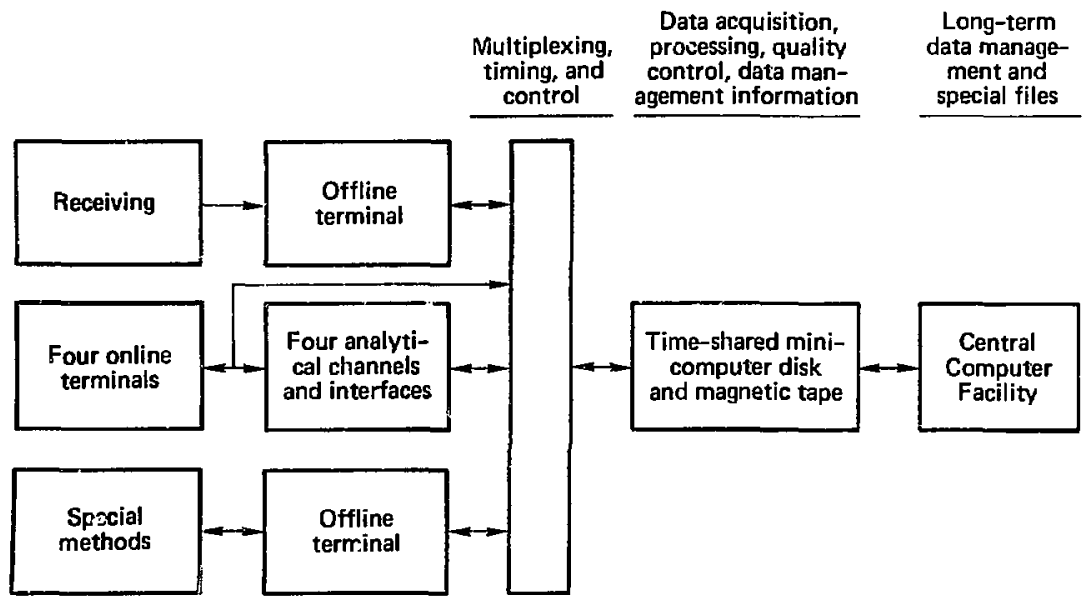

FIG. 2. System 1, which incorporates a time-shared minicompater. 


\section{System 1A, A Variation of System 1}

in-house data management is excluded from the system in favor of data inanar 'ment at LeRC's Central Computer Facility. A time-share computer wouid be u:ed only for data acquisiticn, processing, and control for the high-use instruments.

\section{Advanleges of System 1}

- The systern can be added to in steps.

- A minimum version of the system can service all of the high-use instrumenta? methods on a tirieshare basis.

- The system is similar to other systems developed $i \sim$ the EPA's and USGS's water analysis laboratories. Therefore, certain hardware and software developments are transferable, with some savings in cost.

\section{Disadvantages of System 1}

- There is no backup for system downtime. When the system is being altered or repaired, in- struments must wait. System programining must be scheduled carefully.

- The question of response time for the individual user becomes critical as more and more instruments are added to the system and if extensive data management is on the system.

- Although the orderly approach is possible from the instrument point of view, a la:ge ALS host computer complicates orderly automation because the computer itself is such a large part of the overall system.

\section{System 2}

Figure 3 shows System 2, in which the fundamental building block is the microcomputer with a mass-memory device. The system comprises multiple units of the $f$ undamental building block for online acquisition and processing of data from individual analytici $\mathbb{l}$ instruments. The system also includes a central microcomputer for data collection.

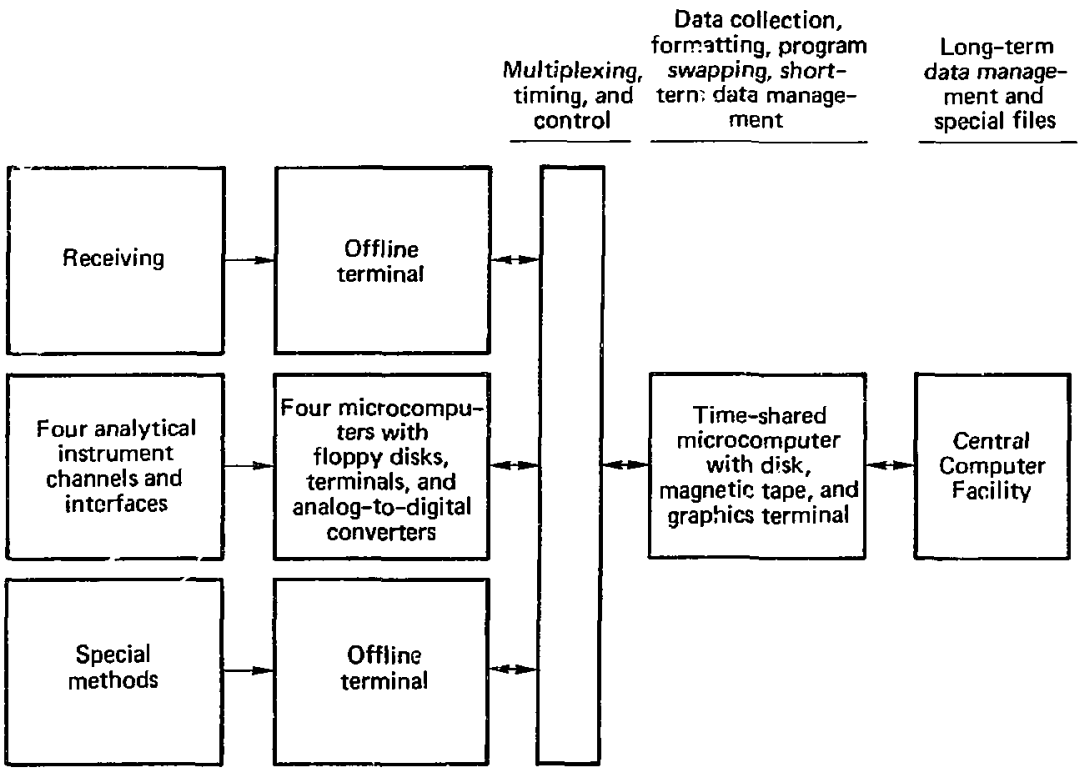

F5G. 3. System 2 point-10-point network, which incorporates a time-shared microcomputer with a massmemory device. 
The central microcomputer is equipped with disk, magnetic tape, and essential input/output covices. Additional input/output terminals are provided for the receiving section and other laboratory sections and for the entry of offline information and data into the data collect,on system.

A number of features should be incorporated into the system. The microcomputer should include a terminal with graphics capability, a mass-memory device (e.g. . Hoppy disk) for each microcomputer, and a capability for programming in a high-level language. These features provide convenient operation and interaction, the capability to write and modify programs with relative ease, and facilities ior backup storage of data.

The input/output terminals for offline use by thr: receiving seci: x: and non-automated instru:nents and methods should include local memory (floppy disks) for backup storage and, if equipped with cathode-ray tube (CRT) display, the ability to view selected lines of a large data set.

The data collection system should contain programs for the reduction of data entered from the offline instruments and special methods.

\section{Variations of System 2}

One variation of System 2 would be to provide two online microcomputer systems for the high-use analytical instruments and two "roll around" systems to be used where needed for current requested analyses. Such a system could be adopted instead of a hardwired microcomputer as shown in Fig. 3. The costs would be comparable to System 2.

Another variation of System 2 incorporates distributed microcomputers (Fig. 4). Each laboratory instrument has its own microcomputer for data acquisition, processing, and control. This allows any one of the microcomputers to be used for any instrument or special function when not busy otherwise. At this writing, automatic switching of the interconnected microcomputers from one duty to another is not fully proven, and the costs associated with this system are also comparable to those for System 2. With the rapidly advancing state of the art, automatic switching may well be available before the end of a several-year project and should be kept in mind.

A central microcomputer controls communications, the data base functions, and the expensive shared peripherals.

\section{Advantages af System 2}

The microcomputer system has the following advantages:

- The building-blozk units allow for ordcrly automation.

- Each unir provides datá storage backup for each analytical inst:ument by ineans of a floppy disk.

- Each unit is relatively inexpensive. Thus, the laboratory is able to retain a standby unit in the event of failure of an online unit.

- The small dimensions and weight of cach building-block unit permit roll-around automation systems that may be linked to an analytical instrument temporarily in high use.

\section{Disadvantages of System 2}

- A complete system for all instruments might be considered expensive.

- There is a limit to the memory in each microcomputer unit for storing a program. Certain instrumental methods require large applications programs that, if placed in a microcomputer system, would have to be segmented and chained into the core from a floppy disk, which may be too slow for good operation.

- Although a single microcomputer unit is relatively small when physically compared with a minicomputer, a number of $t^{\prime}$ in with peripherals may occupy too much space \&) he laboratory.

- A microcomputer systein in the laboratory will be exposed to acid fumes, etc. Thus, wch system may require an enclosure to protect it from the laboratory environment.

- The relatively large number of building blocks in the system increases the likelihood of maintenance problems.

\section{System 3}

System 3 (Fig. 5) is an expanded version of System 2. All instruments would have microcomputers for local data processing and control and be connected to a large central minicomputer. This complete system would include the four instruments mentioned for the other two alternatives and also the electron microprobe, the transmitting electron microscope, the ultraviolet-visible spectrophotometer, an electronic balance, a plate reader and data links for an inductively coupled plasma spectrometer, and a scanning electron microscope. In 


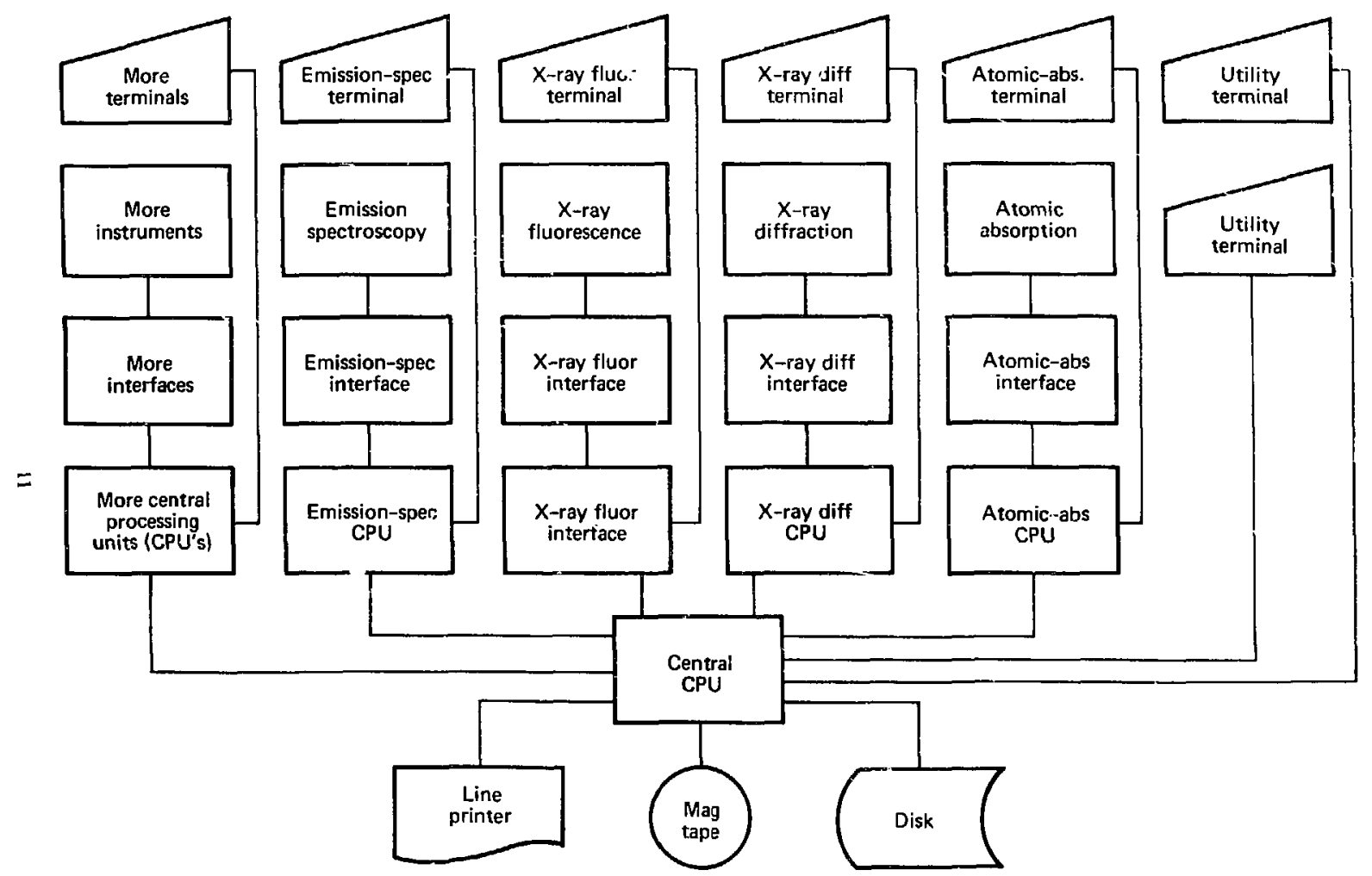

Fis. 4. System 2 interconnected network, which incorporates distributed microcomputers. 


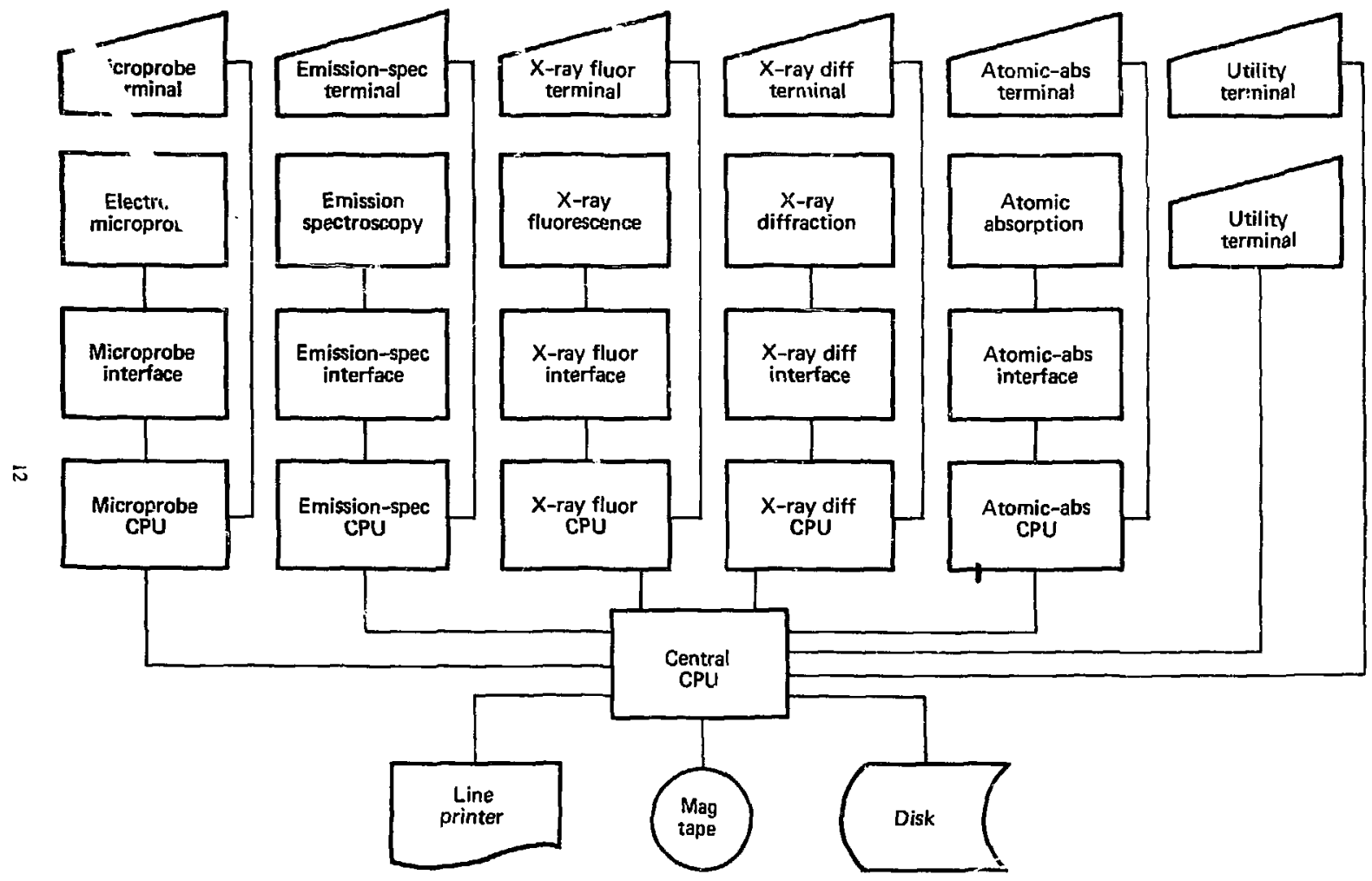

FiG. 5. System 3, the recommended ALS system, which is an expanded version of system 2. All instruments, which have microcomputers for local data processing and control, are connected to a largé central minicomputer. 
addition, complete software including data management software would be made available.

This system shows a later step in evolution under an orderly automation procedure.

In devising concepts of systems to fulfill ALS's requirement 5 , the following three factors weigh heavily:

a The nature of the laboratory samples is such that the systems proposed must be capable of easily managirg a variety of methods and programs for each instrumene.

- Quality assurance requires reasonably capable computational ability and access to the historical record online.

- The capability to build the system in an orderly manner, gradually bringing new instrumentr into the system, is most important for this type of laboratory.
In view of the above factors, small multicomputer aufomation systems appear to be superior to a larger centralized computer automation system. They allow for automation of the most critical and most frequently run analyses as a first step, with the option to expand the system to a network of $\mathrm{ccm}_{\mathrm{m}}$ puters that includes other analyses and more complicated data management procetures.

The benefits of the alternative systems are discussed in the next section. Details of the costs and manpower effort saved are presented in the appendices. Although we show specific vendor equipment costs, these are not intended to reflect vendor recommendations, but rather to show typical costs for the items. The particular vendors should not be selected until definition of functional requirements for each component and implementation designs for the system are completed.

\section{BENEFIT ANALYSIS}

\section{INTRODUCTION}

Two alternate automation systems with variations have been proposed to fulfill ALS needs. In this section we summarize the benefits and expenses from the more detailed accounting found in appendices A, B, and C. Also, we include the cost of a comple : sly automated system (Alternative 3).

\section{BASIS FOR ANALYSIS}

The number of determinations for each instrument is based on information furnished by ALS personnel for 1977. For some techniques we used estimates of the number of determinations based on a fraction of the original estimate since the proposed alternatives would not cover all methods on some of the instruments. This was especially true of $x$-ray diffraction, where there are a number of different procedures used, and emission spectroscopy, where there are two methods used. Also, the directreading emission spectrometel is online already, and some benefits from automation .". now present.
Although quality control is not formalized because of the variety of samples analyzed by ALS, we have assumed that between $S$ and $10 \%$ of the total analysis effort is devoted to cuaiity control.

This study uses two alt:rnate methods of computerization with variations. Both methods provide an ALS host central computing facility that would eventually take care of all the instruments surveyed. Both methods provide orderly automation, which could be extended as time and resources permit. The large initial cost of the centralized computer alternative must be viewed with the realization that it already contains much of the potential for future expansion. In part, the reason for the smaller apparent cost of the distributed microconputer system is because in general one microcomputer will be used by ach instrument, and all of the candidate instruments are not included in this study. A cost difficult to quantify, and not included in the centralized computer alternative, is the cost of disrupting existing operations each time a new instrument is added to the system. This hidden cost is not incurred with the distributed microcomputer system. 
All of the alternatives contain some kind of data manageinent facility either by direct processing or by communicating to the central computer facility of thic Computer Services Division. We expect that daily logging of samples and the workload listing will be done locally and that statistical studies and special sorting will be done remotely.

We recommend thai ALS automation be done by distributed microcomputers for the following reasons:

- The constantly changing mix of sample types demands a versatile, easily manipulated automation system.

- The large number of techniques used at one time or another suggest a system that can quickly be altered from one configuration to another.

- Since it is not reasonable to automate all the instruments at once, the microcomputer concept allows an orderly development of an eventually complete automation system.

- The provision of one added system as a backup replacement greatly enhances the availabilily of the system.

- The central computer concept is still preserved in the idea of a central microcomputer system for data recording and formatting and for program storage and exchange. A large central minicomputer could be used here as in Alternative 3 , if the system some day grew too large for a central microcc mputer.

Figure 5 presents the recommended ALS system, with the electron microprobe added to show how the system could be expanded into Alternative 3.

\section{PROPOSALS}

The recommended computer system initially automates four instruments and provides some data management capabilities. This might be considered phase 1 of the automation project, and as such, the costs are calculated on this basis.

We also suggest two joint development projects between LLL's chenistry departments and LeRC's ALS. One would be the development of a photographic plate reader, and the other would be the development of suitable search soitware for intensity (I) vs angle (28) x-ray diffraction dala.
LLL's Ceramics and Mer allurgy Division has expressed interest in such an effort. The cost and timetable of these projects would be develope ${ }_{\alpha}$ a a part of the functional description phase of the individual proposals; however, the first phase of the automation project should be carried out with these proposals in mind.

\section{BENEFITS}

Table 1 summarizes benefits expressed as increased efficiency. We assumed a tota. effort of 0.3 full-time employee (FTE) for various quality conrool tasks, such as monitoring standards and running checks. We estimate that this effort is reduced by one-half with automation. The details of the rest of the trenefits are in Apperdix C.

A summary of one-time expenses is in Table 2 , along with the expenses for Alternative 3 , for an interim and a conplete system. As mentioned above, the large initial price for the central computer system allows for future expansion.

Table 3 summarizes benefits vs expenses. We believe this is a conservative estimate. It only allows for those measurements and operations est mated from the previous year and for the four cancislate instruments. Note that there are some benefits of computer automation that cannot be included in a

TABLE 1. Summary of estimated savings in worktime requirements at ALS with the proposed system.

\begin{tabular}{lc}
\hline & $\begin{array}{c}\text { Full-1ume } \\
\text { employee } \\
\text { (FTE) }\end{array}$ \\
\hline Atomic absorption & 0.24 \\
Emission spectroscopy & 0.56 \\
X-rny fluorescence & 0.41 \\
X-ray difiraction & 0.40 \\
\multicolumn{1}{c}{ Subtotel } & 1.61 \\
Work-Ilme saved by antomnted & \\
management functions & 0.39 \\
\hline \multicolumn{1}{c}{ Subtotal } & 2.00 \\
Work-time saved by quality & \\
contrel monitoring & 0.15 \\
\hline
\end{tabular}


TABLE 2. Summary of one-time costs for the three options (ahousands of dollars).

\begin{tabular}{|c|c|c|c|c|c|}
\hline & $\begin{array}{c}\text { OptJon I: } \\
\text { centra! } \\
\text { computer } \\
\text { with fulJ dats } \\
\text { management }\end{array}$ & $\begin{array}{l}\text { Oplion IA: } \\
\text { central } \\
\text { compoter } \\
\text { with lfmifed data } \\
\text { mangement }\end{array}$ & $\begin{array}{c}\text { Option 2: } \\
\text { microcomfiaters } \\
\text { a each lastrument } \\
\text { and cen Iral } \\
\text { wlcrocomputer }\end{array}$ & $\begin{array}{l}\text { Option } 3 \text { (phese 1): } \\
\text { 'nicracomputers } \\
\text { nt each instrument } \\
\text { ond aentru } \\
\text { computer with } \\
\text { partial duta } \\
\text { rannagemea! }\end{array}$ & $\begin{array}{l}\text { Option } 3 \text { (complete): } \\
\text { wlcrocomputers at } \\
\text { esch instinment end } \\
\text { cenaral computer } \\
\text { with full data } \\
\text { matragement }\end{array}$ \\
\hline Hardware and peripherals & 120.5 & 102.9 & 85.4 & 225 & 364 \\
\hline Instrumeal interfaces & 19.8 & 19.8 & 19.8 & 30 & 80 \\
\hline Software & 186.0 & 186.0 & 156.0 & 200 & 665 \\
\hline Site preparation & 20.0 & 20.0 & $2 \%, 0$ & 30 & 40 \\
\hline Installation & 33.5 & 33.5 & 33.5 & 50 & 60 \\
\hline Spare parts & 10.0 & 10.0 & 10.0 & 15 & 20 \\
\hline Total & 389.8 & $37 \%, 2$ & 324.7 & $5 S 0$ & 1229 \\
\hline
\end{tabular}

${ }^{a}$ Includes microprobe and ultraviolet-visible spectrophotometer instunents plus a PDP-11/io as tise central compuler.

TABLE 3. Summary of costs and work-time benefits.

\begin{tabular}{|c|c|c|c|}
\hline & Option 1 & Option 1A & Option 2 \\
\hline $\begin{array}{l}\text { One-tires system costs } \\
\text { (thousends of dollars) }\end{array}$ & 389.8 & 372.2 & 324.7 \\
\hline $\begin{array}{l}\text { Ouisiap :agivtenance } \\
\text { (thousands of dollars) }\end{array}$ & 11.2 & 9.7 & 9.6 \\
\hline $\begin{array}{l}\text { Gross annual gavings } \\
\text { (FTE) }\end{array}$ & 2.15 & $? . .5$ & 2.15 \\
\hline $\begin{array}{l}\text { Annual expenditures } \\
\text { (FTE) }\end{array}$ & 9.60 & 0.35 & 0.35 \\
\hline $\begin{array}{l}\text { Ne1 annual savings } \\
\text { (FTE) }\end{array}$ & 1.5 ? & 1,8 & 1.8 \\
\hline
\end{tabular}

cosi factor study. Such benefits include fewer transcription errors, staff access to an easily programmable problem-solving computer, shorter turnaround time between sample in and report out, and more attention devoted to analytical methodology. In addition, the computer can be an educational tool of great value to analytical chemistry personnel if they have easy access to it. The large number of currently available calculaticnal and statistical programs leric themselves to analytical applications and provide the analyst with the mea: is for further pursuing automation studies. 


\section{APPENDIX A. BREAKDOWN OF ONE-TIME COSTS FOR SYSTEMS AND THEIR VARIATIONS}

\section{COMPUTERS AND PERIPHERALS}

The costs for the computers and peripherals for the threc proposed automation systems and their variations are in Tables $A-1$ and $A-2$. Bear in inind that specific vendor equipment is presented to show typical costs and is not a recommendition.

The computer for the first option is an ECLIPSE C/330 as used in the current EPA and USGS systems. It may be used in a background time-shared foreground mode running under a realtime disk operating system. This mode of operation supports extended BASIC time-share automation. The $\mathrm{C} / 330$ also supports software for database management, communications to other computers, and an advanced operation system. The 128 kilobytes of core is recommended if an exiensive sata management system is to be used with this system. For the variation on this first option the smaller ECLIPSE S/230 has many of the same features, but lacks full data management capability.
For system 2 we use the DEC LSI-11 as a representative microcomputer. This is a powerful microcomputer system that also supports a timeshared environment.

For system 3, the complete system, we have used the PDP $11 / 70$ as a representative central minicomputer. This system includes all instruments, a plate reader, and complete software for $x$-ray procedures and data management. Combined expenses for this system are in Table A-3.

We propose the following peripheral equipment for Option 1.

\section{Disk Storage}

The disk system provides a rapid-access storage of programs and data. We recommend a movinghead disk because of its fast data transfer properties. The proposed version for the first alternative incorporates the Data General model $\mathbf{6 0 6 0}$ movinghead disk with a storage capacity of 96 megabytes.

TABLE A-1. Cost of computar hardware and peripheral equipment fer Option 1.

\begin{tabular}{|c|c|}
\hline & $\begin{array}{c}\text { Cost } \\
\text { (thonsands of dollers) }\end{array}$ \\
\hline Computer Data General ECLIPSE C/330, 128-kilobytes core memory and memory ragp & 35.7 \\
\hline Moving-head disk, 96 megabytes & 21.9 \\
\hline Magnetic tape, 9-treck & B.d \\
\hline Line printer, 300 lines/min & 10.6 \\
\hline Papertape reader & 1.7 \\
\hline Sysiem cabinet, 3-bay & 3.0 \\
\hline Eight-line programmable multplenor & 4.1 \\
\hline Communications Interface to LeRC's Central Computer Facility & 2.0 \\
\hline Anglog-to-digltal convertes, 16-channel & 6.2 \\
\hline Advanced Operatlag System software & 4.9 \\
\hline Other system software & 1.0 \\
\hline Vour Texas Instruments tenuinals (B) \$1500 each & 6.0 \\
\hline One graphles terminol & 12.0 \\
\hline Two screen-type terminals & $\mathbf{3 . 0}$ \\
\hline Total for Opton i & 120.5 \\
\hline \multicolumn{2}{|l|}{ For Option IA substitnte: } \\
\hline $\begin{array}{l}\text { Computer Data General ECEJPSE/230, 96-kilobytes core memory and memory map } \\
\text { without AOS softu are }\end{array}$ & 23.0 \\
\hline Total for Option ih & 102.9 \\
\hline
\end{tabular}


TABLE A-2. Cost of computer hardware and peripherils for Oplion 2.

\begin{tabular}{|c|c|c|c|}
\hline & $\begin{array}{c}\text { Casi } \\
\text { (thousands of dollans) }\end{array}$ & Qunotíty & $\begin{array}{c}\text { Total } \\
\text { (thoosands of doltars) }\end{array}$ \\
\hline $\begin{array}{l}\text { LSI-11 with 28-kilobytes core and dual floppy } \\
\text { dibks }\end{array}$ & 4.95 & 5 & 24.8 \\
\hline Moving-hiad disk, DEC R-11-AR, 10 megabyles & 8.9 & 1 & 8.9 \\
\hline $\begin{array}{l}\text { Regoetic tope, DEC TMP-11Y }, \text { 9-track, } \\
\text { 80:0 bits/la. }\end{array}$ & 7.6 & $\mathbf{1}$ & 7.6 \\
\hline Lipe printer & 15.0 & 1 & 15.9 \\
\hline System cabinel & 0.37 & 4 & 1.5 \\
\hline Texes Instruments termianals & 1.5 & 4 & 6.0 \\
\hline Screen termlina] & 1.5 & 2 & 3.0 \\
\hline Grapbics termingl & 12.0 & $\mathbf{1}$ & 12.0 \\
\hline Analog-to-digital converters, J4-sjt & 0.25 & 4 & 1.0 \\
\hline Subtatal & & & 79.8 \\
\hline Software, RT-21, QJ013-AY & & & 2.8 \\
\hline Soitware, BASIC, 0S913-AY & & & 0.8 \\
\hline Software, FORTRAN, Q5980-AY & & & 0.9 \\
\hline Software, Multitask, QJ945-AY & & & 1.1 \\
\hline Subtatal & & & 5.6 \\
\hline Total & & & 85.4 \\
\hline
\end{tabular}

Magnetic Tape

Magnetic tape is used as the primary backup medium for the system. It is also important for long-term bulk strage and for the transfer of data from one location to another.

\section{Line Printer}

The line printer is needed to produce workload listings, sample loading patterns, notebook results, final results and progress reports, as well as a listing of programs. The line printer should print at 300 lines $/ \mathrm{min}$.

\section{Papertape Reader}

The papertape reader is used for system startup and to load diagnostic pregrams when the disk or tape is not available.

\section{Analog-10-Digital Converter System}

The analog-to-digital converter reads signals coming from the automated instruments. The proposed converter has a resolution of one part in $16,384\left(2^{14}\right)$ of a full-scale signal. We feel 16 channels should be present for system expansion and alternate use in case of malfunction.
Option 2 has similar peripheral equipment at the central microcomputer. Because each microcomputer has a dual-floppy disk systemn, a smaller central disk is specified. Also, a papertape reader is not specified here for ine same reason. The analogto-digital converter is a smaller version of the system proposed for Option 1. Since for Option 1 an analog-to-digital converter for each instrument is necessary, four will be required.

Both options require the same terminals.

\section{Terminals}

The terminals are the majo: means of entering information into the computer system other than the analog-to-digital converter. They are also used to report interim data and to issue warnings during automated runs.

We propose three different terminal types. One is a quiet hardcopy device. This is often used with the computer console to control system operation. A switch can be provided for hackground/foreground operation.

The second type of terminal is a CRT screen device. This type has the advantages: of more rapid 
TABLE A-3. Combined costs for System 3 (thousands of 1978 dollars).

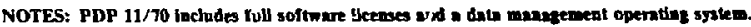

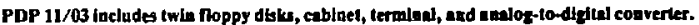

YEAR. indkates subcategorles of expenes.

.0 Commercial bardwere and sotware

.1 Spectalized hardware

.2 Softwere development and documeatation

.3 Site preparntion such es alr conditioalag, electrol anply, etc.

4 Instillacios

5 Spare parts

\begin{tabular}{|c|c|c|c|c|}
\hline Year.\# & Item & Cost & Quantity & Totel coet \\
\hline 1979.0 & PDP 11/70 & 115 & 1 & 115 \\
\hline 1979.0 & Mag upe & 15 & 1 & is \\
\hline 1979.0 & L.sneprinter & 15 & 1 & 15 \\
\hline 1979.0 & Disk storage & 25 & $\mathbf{1}$ & 25 \\
\hline 1979.0 & DBMS nystem & 10 & 1 & I0 \\
\hline \multirow[t]{2}{*}{1979.0} & PDP 11/03 & 9 & 5 & 45 \\
\hline & Subtots & & 10 & 225 \\
\hline I979.1 & Atomic-2bsorpsion spectrophotometer (AAS) Interface & $\mathbf{5}$ & 1 & 5 \\
\hline 1979.1 & Embslon spectroscopy (EMSPEC) Interfece & $\mathbf{s}$ & 1 & 5 \\
\hline 2979.1 & Dhano X-ray fuorescence (XRP) juterfaue & $\mathbf{s}$ & 1 & 5 \\
\hline 1979.1 & $\mathrm{X}$-ray diffraction (XRD) interf mee & $\mathbf{5}$ & 1 & 5 \\
\hline 1979.1 & Microprobe interface & 5 & 1 & 5 \\
\hline \multirow[t]{2}{*}{1979.1} & Uluraviolet-v|sible (UV-YIS) Interface & $\mathbf{s}$ & 1 & 5 \\
\hline & Subtotal & & 6 & 39 \\
\hline 1979.2 & DBMS Bottware & so & 1 & 50 \\
\hline 1979.2 & AAS cottrare & 25 & 1 & 255 \\
\hline 1979.2 & EMSPEC software & 25 & $\mathbf{1}$ & 25 \\
\hline 1979.2 & Dlana XRF software & 25 & 1 & 25 \\
\hline 1979.2 & XRD sof tware & 4 & 1 & 40 \\
\hline 1979.2 & Microprobe software & 10 & 1 & 10 \\
\hline \multirow[t]{2}{*}{1979.2} & UV-VIS software & 25 & 1 & 25 \\
\hline & Subtotel & & 7 & 200 \\
\hline \multirow[t]{2}{*}{579.3} & Site preparation & 30 & $\mathbf{I}$ & 30 \\
\hline & Subtoted & & 1 & 30 \\
\hline \multirow[t]{2}{*}{1979.4} & Installation & So & $\mathbf{1}$ & 50 \\
\hline & Subtotal & & 1 & $50^{-}$ \\
\hline \multirow[t]{2}{*}{1979.5} & Spare parts & 15 & 1 & 15 \\
\hline & $\begin{array}{l}\text { Subrotal } \\
\text { Yeser total }\end{array}$ & & $\begin{array}{r}1 \\
26\end{array}$ & $\begin{array}{r}15 \\
550\end{array}$ \\
\hline 1980.0 & PDP 11/03 & 9 & $\mathbf{5}$ & $\mathbf{4 5}$ \\
\hline 1980.0 & Lneprinter & 15 & $\mathbf{1}$ & 15 \\
\hline 1980.0 & Grapules terminals & 12 & 2 & 24 \\
\hline \multirow[t]{2}{*}{1980.0} & XRC/ search system & 25 & 1 & 25 \\
\hline & Subtotel & & 9 & 109 \\
\hline 1980.1 & Balacese interface & $\mathbf{s}$ & 1 & 5 \\
\hline 1980.1 & Inductively coupted plesma (RCP) Interface & $\mathbf{5}$ & 1 & $\mathbf{s}$ \\
\hline \multirow[t]{2}{*}{1980.1} & Microprobe apgande & 25 & $\underline{1}$ & $\mathbf{2 5}$ \\
\hline & Subtotal & & 3 & 39 \\
\hline 1980.2 & Dlano XRF sciftware & 25 & 1 & 25 \\
\hline 1980.2 & XRD softwan: & 40 & $\mathbf{1}$ & 40 \\
\hline 1980.2 & Balance softm are & 25 & I & 25 \\
\hline 1980.2 & XRD search sifftware & so & 1 & so \\
\hline
\end{tabular}


TABLE A-3. Continued.

\begin{tabular}{|c|c|c|c|c|}
\hline Year." & Item & Cost & Quentity & Toteleast \\
\hline \multirow[t]{2}{*}{1980.2} & $\begin{array}{l}\text { ICP software } \\
\text { DBMS software }\end{array}$ & $\begin{array}{l}10 \\
40\end{array}$ & $\begin{array}{l}1 \\
1\end{array}$ & $\begin{array}{l}10 \\
40 \\
\end{array}$ \\
\hline & Subtolnl & & 6 & 190 \\
\hline \multirow[t]{2}{*}{1980.3} & Site prepanation & 10 & $\therefore$ & 10 \\
\hline & Subtotal & & 1 & 10 \\
\hline \multirow[t]{2}{*}{ 1990.4 } & Installation & 10 & 1 & 10 \\
\hline & Subtotal & & 1 & 10 \\
\hline \multirow[t]{2}{*}{1980.5} & Spare parts & 5 & 1 & 5 \\
\hline & $\begin{array}{l}\text { Subtotal } \\
\text { Year tutal }\end{array}$ & & $\begin{array}{r}1 \\
21\end{array}$ & $\begin{array}{r}5 \\
359\end{array}$ \\
\hline \multirow[t]{2}{*}{1981.0} & Plate-reader system & $\mathbf{3 0}$ & 1 & 30 \\
\hline & Subtotal & & 1 & 30 \\
\hline \multirow{3}{*}{$\begin{array}{l}1981.1 \\
3983.1\end{array}$} & Plate-rader interface & 10 & 1 & 10 \\
\hline & 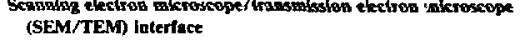 & 5 & 1 & $\mathbf{s}$ \\
\hline & Subtotal & & 2 & 15 \\
\hline 1981.2 & Plate-render software & 150 & 1 & 150 \\
\hline 1981.2 & XRD search software & 50 & 1 & 50 \\
\hline 1981.2 & SEM/TEM software & so & $\mathbf{I}$ & so \\
\hline \multirow[t]{4}{*}{1981.2} & Graphios soltware & 25 & 1 & 25 \\
\hline & Subtotal & & 4 & 275 \\
\hline & Year rotal & & 7 & 320 \\
\hline & Grand Is:al & & 45 & 1229 \\
\hline
\end{tabular}

display and not creating large amounts of unneeded paper. Some have the ability to roll back, that is, redisplay information already scrolled off the screen.

A graphics terminal would also be provided for special uses. It should be an intelligent termina! similar to the Tektronix $\mathbf{4 0 5 1 .}$

Wc recommend seven termina's for the first two options: one graphic terminal and one CRT type for sample logging, four terminals (two of each type) for instruments and an extra terminal for the console.

\section{INSTRUMENT INTERFACES}

For Option 1 some of the existing interface designs from previous installaticas are applicable. For Option 2, however, it will be necessary to redesign the general computer interface. We anticipate that the existing laboratory instrument interface designs, where they exist, will be applicable to either the LSI-11 system or the ECLIPSE system. Costs are summarized in Table A-4.

\section{SOFTWARE}

Option 1 assumes the application programs are written in Data General extended BASIC for a realtime disk operating system (RDOS) environment.

TABLE A-4. Summary of interface design and fabrication costs (thousands of dollars).

\begin{tabular}{lcc}
\hline \multicolumn{1}{c}{ Type of interface } & Optlon 1 & Optina 2 \\
\hline General interiace design & - & 6.0 \\
General interface fabrication & 9.3 & 9.3 \\
X-ray flaorescence fabrication & 3.0 & 3.0 \\
X-ray diftraction fabrication & 3.0 & 3.0 \\
Atomic-absorption fabrication & 1.5 & 1.5 \\
Emission spectrometer fabrication & 3.0 & 3.0 \\
\hline
\end{tabular}


Option 2 assumes the application programs are written in LSI-11 BASIC or FORTRAN. For these latter options, FORTRAN or some other high-level language becomes a viable alternative because each instrument will be operating independently of the c thers. In any case, the language chosen for Option 2 will take advantage of software availability. $f t$ present, we expect $x$-ray application programs to be written in FORTRAN.

In the case of Option 1, existing laboratory application programs are available for the atomicabsorption instrument. We have estimated costs at about $20 \%$ of the riginal software cost for modirications that might de necessary. Programs also exist for emission spectroscopy. Modifications wuuld be expecter here alsn, and we estimate this cost to be comparable to atomic-absorption modifications. For Uption 2, we estimate that translating the existing programs will double the cost.

The $x$-ray fluorescence programs have not been written for this system. We assume, however, some savings coming from modification of existing software that will be available from LLL's automation effert in metallurgy and ceramics, particularly for the matrix-correcting programs. Once the data is collected and corrected for matrix effects, the program for calculating answers follows a straightforward standards calibration curve. We estimate that these programs would contain about 1000 lines of BASIC or about one man-year of effort, or $\$ 60,000$. Adding $20 \%$ for modifying the existing matrix corrections programs brings the total to $\$ 72,000$. Much of this work will be available from
LLL, although it will probably have to be modified for Option 2. We estimate about balf the above total will juer the high-level language for $x$-ray fluorescence for Option 1. For Options 2 and 3, the programs should be more readily available from LLL, and an estimate of half the cost of Option ! seems reasonable.

The $x$-ray diftraction programs also have to be completely written. A situation similar to $x$-ray fluorescence can be anticipated. The complete $x$-ray diffraction program would have to be developed in steps, and the cost here is only for the first step (preparing a table of intensity is $2 \theta$ values). Estimation comes f:om assuming twice the cost of the assembly language routines $f(x) x$-ray fluorescence and about $40 \%$ more for the advanced language routines.

A good portion of the data management programs will come from those already established for the USGS automation project. We have estimated $\$ 20,000$ for this conversion for Option 1 . In the case where data management will be done at the central computer facility, we assume that some of the cost will be borne by the computer facility and estimate $\$ 20,000$ here also. In any case, software protocol will have to be developed for communicating with this facility. Wre have estimated a total of $\$ 10,000$ for this software. Software is ivailable for communicating with a central mini- is micro-computer and for networking. We estimate $\$ 10,000$ for implementing these systems. Table A-5 shows the estimated software costs for the different options.

TABLE A-5. Cost of computer software (thousands of dollars).

\begin{tabular}{|c|c|c|c|c|c|}
\hline \multirow{2}{*}{\multicolumn{2}{|c|}{ Lescription }} & \multicolumn{2}{|c|}{ Option 1} & \multicolumn{2}{|c|}{ Option 2} \\
\hline & & Assembly & Highl-level & Asscmbly & High-level \\
\hline \multicolumn{2}{|c|}{ Insirumentation Laboratory AA spectrophotometer } & 2.5 & 10 & 5 & 20 \\
\hline \multicolumn{2}{|c|}{ Jarrell-AsL 1.5-m emission spectrometer } & 2.5 & 10 & $s$ & 20 \\
\hline \multicolumn{2}{|c|}{ Diano xRD-8000 x-ray fluorescence } & 15 & 36 & 8 & 18 \\
\hline \multicolumn{2}{|c|}{ X-ray diffraction (direct) } & 30 & $\mathbf{5 0}$ & 15 & 25 \\
\hline \multicolumn{2}{|l|}{ Data management } & & 20 & & 20 \\
\hline \multicolumn{2}{|c|}{ Link or network or both } & & & 10 & \\
\hline \multicolumn{2}{|c|}{ Communication to Ceniral Computer Facility } & & 10 & & 10 \\
\hline Totals & & so & 136 & 43 & 113 \\
\hline Oplions 1 and $1 \mathrm{~A}$ & 186 & & & & \\
\hline Option 2 & 156 & & & & \\
\hline
\end{tabular}




\section{MISCELZANEOUS EXPENSES}

These expenses include costs for site preparation, installation, spare parts, and test equipment. Expenses will vary' somewhat for the option selected, but in general we estimate that these differences will not be appreciable except for software maintenance,

\section{Site Preparation}

For Option 1 this is the cost of preparing a room of about $200 \mathrm{ft}^{2}$ to house the computer, with adequate electrical service and air conditioning. It also includes pulling cables from instrument sites to the computer room. A nominal figure is $\$ 20,000$.

For Option 2, using microcomputers, the preparations would be somewhat different. But we will assume that $\$ 20,000$ covers such concerns as proteeting the microcomputers from laboratory environment and establishing work areas.

\section{Installation}

This cost is estimated to be $\$ 33,500$, based on previous installations. It includes shipment of the system, installation at the ALS laboratory, hardware and software checkout, operational testing, and training personnel.

\section{Spare Parts and Test Equipment}

To maintain the system, a minimum complement of spare parts and test equipment must be acquired. Spare parts should include items such as control logic cards, power supplies, operational amplifiers, relays, and connectors. The cost for a recommended quantity of these items is about $\$ 3,000$. The major test equipment item, an oscilloscope, will cost about $\$ 7,000$. Thus, $\$ 10,000$ to $\$ 20,000$ should be set aside for spare furts and test equipment. 


\section{APPENDIX B. ADDED OPERATING COSTS FROM AUTOMATION}

The proposed automation systems will add new costs to the annual operating costs of the ALS laboratory. These costs will mainly be for the maintenance of computer hardware and peripherals and for laboratory instrument hardware interfaces and software. The annual operating costs that reflect the above requirements for Options 1 and 2 are in Table B-1.
Software maintenance will depend on the option selected. For a full-fledged data management and operating system, we estimate 0.5 FTE. For mainter ance of ipstrument software with data management at a remote facility, 0.25 FTE seems reasonable. Electronic maintenance of interfaces, cabling, and miscellaneous components wi:. require another 0.1 FTE.

TABLE B-1. Annual operating costs and work-time for Options 1 and 2.

\begin{tabular}{|c|c|c|c|}
\hline Calegory & Gption IA & Optlon IB & Option 2 \\
\hline $\begin{array}{l}\text { Vendor-supplied maintenance of computer, peripherals, and soltwore (thousands of } \\
\text { dollars) }\end{array}$ & $11.2^{2}$ & $9.7^{2}$ & $9.6^{b}$ \\
\hline \multicolumn{4}{|c|}{ 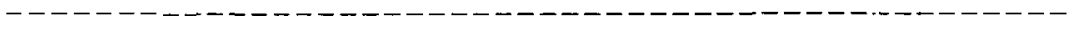 } \\
\hline In-house maintenance of interface hardware (FTE) & 0.1 & 0.1 & 0.1 \\
\hline Seme for soltware (TTE) & 0.5 & 0.25 & 0.25 \\
\hline Total FTE: & 0.6 & 0.35 & 0.35 \\
\hline
\end{tabular}

\footnotetext{
astimated at $12 \%$ per year of compuler hardware and peripherals not includiag terminals or software.

bestimated by Digital Equipment Corporation representative.
} 


\section{APPENDIX C. DETAILED ASSESSMENT OF AUTOMATION BENEFITS}

To assess the benefits that will accrue to ALS as a result of automation, we compared the manual effort (no automation) that will be required to meet the expected workload in the candidate instrumental analysis and sample coordination and management areas with the effort we project will be required if automation is implemented. Effort here is defined as the time required for an employee to perform a task and is expressed as multiple or fractional full-time entployee (FTE) or both. We examined the detailed procedure tasks associated with the instrumental methods and sample management processes that are candidates for automation. For each candidate instrument, only those tasks that can be fully or partially automated will be more effort-efficient.

\section{INSTRUMENTAL METHODS}

We have adopted a model to calculate the effective time required of a chemist to make a determination using any of the candidate instruments. The model takr:s into consideration the maltifle tasks that he inust perform, including factcrs for quality control samples, reruns, and samples that are diluted. With the effective time, and the number of determinations per year, one can calculate the total chemist time in FTE to handle the workload.

The model is used to calculate the effort required for a single determination using manual techniques vs automated techniques. The effective total effort is then calculated, based on a linear relationship between the number of determinations and the effort per determination. It is possible, however, that this relationship would not extrapolate linearly to a higher number or determinations.

It should be remembered that it is the number of determinations that is used for these calculations, not the number of samples. Many samples require multiple analyses for the determination of each requested component, and some samples require several determinations to estimate one component.

The following two equations are used in the model:

$$
t_{s}=p+(1+f)(w+i+c)+f d
$$

where

$t_{\mathrm{s}}=$ total chemist time needed for each determination,

p = time for preparation of sample and logbook per determination,

$w=$ time needed to write log and introduce sample per determination,

$\mathrm{i}=$ chemist time spent in operating the instrument per determination,

$c=$ time needed to calculate and trarsscribe results per determination,

$\mathrm{d}=$ time taken for a single dilution,

and
$f=$ fraction of off-scale samples requiring dilution;

and

$$
e=t_{s}(1+q)(1+r) \frac{H}{H-T_{b}},
$$

where

$e=$ the effective chemist time taken per determination,

$q=$ quality assurance fraction,

$r$ = fraction of samples retested for reasons other than being off-scale,

$\mathrm{H}=$ total average operator time spent for a work session,

and

$T_{b}=$ time to set up instrument at the beginning of each work session, shyr it down at the end, and run standards.

With the model, calculations of the benefits to be realized by automation of the candidate instrumental methods appear in the following four subsections.

The Tables C-1 through C-5 give a breakdown of the tasks involved for each of the four instruments to be automated and a comparison of the effort that will be required by manual methods relative to the effort if automated techniques are developed. 
TABLE C-1. Automation benefits: atomic-absorption spectrophotonceter.

\begin{tabular}{|c|c|c|c|}
\hline $\begin{array}{l}\text { Taik Imes } \\
\text { and time factors }\end{array}$ & Symbol & At present & With automation \\
\hline Preparation of sample (min) & p & 4.9 & 4.9 \\
\hline Write log, introdace sample (min) & 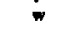 & 1.6 & 0.8 \\
\hline Opention of Insirument by chemist (min) & I & 2.0 & 2.0 \\
\hline Colculatlon 4 trangcription of resplis (min) & c & 4.9 & $\mathbf{0}$ \\
\hline Dilution of one oft-acale sample (mia) & d & 5.0 & 4.0 \\
\hline Faclor for aamples diluted & I & 0.2 & 0.2 \\
\hline Calculated cheraist time per determination (min) & 4 & 16.1 & 9.06 \\
\hline Retest factor & $\mathbf{r}$ & 0.1 & 0.1 \\
\hline Quality control Iactor & $\mathbf{q}$ & 0.1 & 0.1 \\
\hline Setap and shutdown per work session (min) & 8 & 45 & 45 \\
\hline Hours per work sesslon & $\mathbf{H}$ & 6.5 & 6.5 \\
\hline $\begin{array}{l}\text { Calculated effectlve chemist time } \\
\text { per determination (min) }\end{array}$ & e & 22.02 & 12.39 \\
\hline Benerit calculations & & & \\
\hline Number of delerminatlons per chembi day & & 21.8 & $\mathbf{3 6 . 7 3}$ \\
\hline Determingtions per year & & 2734 & 2734 \\
\hline Chemlat days per yenr to meet load & & 125 & 71 \\
\hline Chemlst years to meet load (FTE) & & 0.56 & 0.31 \\
\hline
\end{tabular}

\section{ATOMIC ABSORPTION SPECTROPHOTOMETER}

We used the number of determinations for 1977 as a base for these figures.

\section{EMISSION SPECTROSCOPY}

We used $\mathbf{5 0 0}$ determinations/year as a figure for direct-reading emission spectroscopy. These figures compare an instrument already partially automated.

TABLE C-2. Automation benerits: emission spectrometer.

\begin{tabular}{|c|c|c|c|}
\hline $\begin{array}{c}\text { Thsk times } \\
\text { and time factars }\end{array}$ & Symbol & At present & With antomation \\
\hline $\begin{array}{l}\text { Preparation of sample (min) } \\
\text { Write log, introduce sample (min) } \\
\text { Operatton of instrument by chemist (min) } \\
\text { Calculation \& tmusertptlou of resalts (min) } \\
\text { Dilution of one oflescile wimple (mla) } \\
\text { Factor for samples dilated }\end{array}$ & $\begin{array}{l}\text { p } \\
\text { i } \\
\text { c } \\
\text { d } \\
\text { I }\end{array}$ & $\begin{array}{l}27.0 \\
13.5 \\
168.0 \\
27.0 \\
5.0 \\
0.05\end{array}$ & $\begin{array}{l}27.0 \\
13.5 \\
54.0 \\
0 \\
5.0 \\
0.05\end{array}$ \\
\hline Calculated chemlst tlme per determination (min) & 1 & 183.17 & 93.12 \\
\hline $\begin{array}{l}\text { Retesl factor } \\
\text { Quality control factor } \\
\text { Setup and shotdown per work session (min) } \\
\text { Hours per worl session }\end{array}$ & $\begin{array}{l}r \\
\mathbf{q} \\
\mathbf{s} \\
\mathbf{H}\end{array}$ & $\begin{array}{l}0.01 \\
0.05 \\
90 \\
6\end{array}$ & $\begin{array}{l}0.01 \\
0.05 \\
\approx 73 \\
6\end{array}$ \\
\hline $\begin{array}{l}\text { Calcuiated effective chembt time } \\
\text { per determination (mla) }\end{array}$ & e & 259.01 & 138.75 \\
\hline $\begin{array}{l}\text { Benefit calculations } \\
\text { Number of datermlandions per chemist day } \\
\text { Determinations per year } \\
\text { Chemlst days per year to meet load } \\
\text { Chemist yeans to meet load (FTE) } \\
\text { (Eftort efliclency improvement }=1.2 \sim 0.64=0.56 \text { FTE) }\end{array}$ & & $\begin{array}{l}1.85 \\
500 \\
270 \\
1.2\end{array}$ & $\begin{array}{l}3.46 \\
500 \\
145 \\
0.64\end{array}$ \\
\hline
\end{tabular}


TABLE C-3. Automation benefits: x-ray fuorescence spectroscopy.

\begin{tabular}{|c|c|c|c|}
\hline $\begin{array}{l}\text { Trak times } \\
\text { and IJme factors }\end{array}$ & Symbol & At present & With automation \\
\hline Preparatlon of sample (min) & D & 9.31 & 9.31 \\
\hline Write log, Intraduce sample (min) & 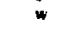 & 3.57 & 1.79 \\
\hline Operation of instrument by chemist (min) & i & 5.0 & 3.0 \\
\hline Calculation \& transcription of results (min) & a & 4.89 & $\mathbf{0}$ \\
\hline Disution of one off-scale sample (min) & d & 5.0 & 5.0 \\
\hline Factor tor s\&mples dlluted & i & 0.17 & 0.17 \\
\hline Calculaled chemist lime per determination (min) & $\mathbf{t}$ & 25.91 & 15.76 \\
\hline Retest factor & r & $\begin{array}{l}0.1 \\
0.1\end{array}$ & $\begin{array}{l}0 \\
0.1\end{array}$ \\
\hline $\begin{array}{l}\text { Quallty control factor } \\
\text { Setup and shuttown per work session (min) }\end{array}$ & $\begin{array}{l}\text { q } \\
\mathbf{s}\end{array}$ & $\begin{array}{l}0.1 \\
95\end{array}$ & $\begin{array}{l}0.1 \\
95\end{array}$ \\
\hline $\begin{array}{l}\text { Setup and shutdown per work session (min) } \\
\text { Hours per wori session }\end{array}$ & H & 4.0 & 4.0 \\
\hline \multicolumn{4}{|l|}{$\begin{array}{l}\text { Cafculated effective chemlst time } \\
\text { per Jetermination (min) }\end{array}$} \\
\hline per Uetermination (min) & e & 51.89 & 28.7 \\
\hline \multicolumn{4}{|l|}{ Benefit calculations } \\
\hline Number of determinations per chemlst day & & 9.25 & 16.72 \\
\hline Determinations per year & & 1891 & 1891 \\
\hline Chernist days per year to meel load & & 204 & 113 \\
\hline $\begin{array}{l}\text { Chemlst years to meet lond (FTE) } \\
\text { (Effort efficiency improvement }=0.91-0.5=0.41 \text { FTE) }\end{array}$ & & 0.91 & 0.5 \\
\hline
\end{tabular}

\section{X-RAY FLUORESCENCE SPECTROSCOPY}

We used the figure for the number of determinations for 1977.

\section{X-RAY DIFFRACTION BY DIRECT READING}

For this study we estimate about 1000 determinations are run by this method, which seems to

TABLE C-4. Automution benefits: x-ray diffraction.

\begin{tabular}{|c|c|c|c|}
\hline $\begin{array}{l}\text { Task times } \\
\text { and time factors }\end{array}$ & Symbol & At present & With gutomation \\
\hline Prepanation of sample (min) & $\mathbf{p}$ & 9.0 & 9.0 \\
\hline Write log, introduce sample (min) & w & 1.2 & 1.2 \\
\hline Operation of instrument by chemist (min) & 1 & 4.8 & 2.0 \\
\hline Catculatlon \& tranacription of results (min) & c & 36.8 & 6.0 \\
\hline Dilluston of onr off resle sample (min) & d & o & o \\
\hline Factor for samples diluted & I & o & 0 \\
\hline Calculated chemist time per determination (mln) & $\mathbf{t}$ & 51.0 & 18.2 \\
\hline Retest factor & $\mathbf{r}$ & 0.01 & $0 . \Omega !$ \\
\hline Qunility control factor & q & 0.1 & 0.1 \\
\hline Setup and shutdowa per work session (m/n) & $\mathrm{s}$ & $\mathbf{3 6 . 0}$ & 36.0 \\
\hline Hours per work session & $\mathbf{H}$ & 4.0 & 4.0 \\
\hline $\begin{array}{l}\text { Cajculated elfeclive cbemist time } \\
\text { per determination (min) }\end{array}$ & e & 66.66 & 23.79 \\
\hline Benefit calculattons & & & \\
\hline Number of de terminations per chemist day & & 3.2 & 20.18 \\
\hline Determlnations per yegr & & 1000 & 1000 \\
\hline Chemist days per year to meet load & & 139 & 50 \\
\hline $\begin{array}{l}\text { Chemist years to meet load (FTE) } \\
\text { (F!fort efficlency improvement }=0.62-0.22=0.4 \text { FTE) }\end{array}$ & & 0.62 & 0.22 \\
\hline
\end{tabular}


TABLE C.5. Management Tasks.

\begin{tabular}{|c|c|c|}
\hline Teskls & $\begin{array}{l}\text { Present } \\
\text { eilon } \\
\text { (FTE) }\end{array}$ & $\begin{array}{l}\text { Elfort } \\
\text { with gutomition } \\
\text { (FTE) }\end{array}$ \\
\hline $\begin{array}{l}\text { Gathering informallon for the } \\
\text { coordination of laboratory activitics }\end{array}$ & 0.38 & 0.19 \\
\hline $\begin{array}{l}\text { Preparing reports of laboratory } \\
\text { getivitles }\end{array}$ & 0.25 & 0.12 \\
\hline Monitoring quality control & 0.13 & 0.06 \\
\hline $\begin{array}{l}\text { Total } \\
\text { (Effor efficiency improvement }=0.39 \mathrm{FTE} \text { ) }\end{array}$ & 0.76 & 0.37 \\
\hline
\end{tabular}

correspond to the statistical data furnished. This is for partial automation. The final matching of intensity vs $2 \theta$ values would be computer. tssisted but not completely automatic.
The estimates in Table $\mathbf{C - 5}$ are for an interactive nnanagement system that would allow a reduction of about half the current effort in monitoring laboratory functions. 